\title{
AFES A.S.-O.N.E.: ASEAN Survey Of Needs in Endocrinology in the Time of the COVID-19 Pandemic
}

\author{
Gabriel Jasul Jr., ${ }^{1,2}$ Elizabeth Paz-Pacheco, ${ }^{1,3}$ Cecilia Jimeno, ${ }^{1,4}$ Ketut Suastika, ${ }^{5}$ Zanariah Hussein, ${ }^{6}$ \\ Norlaila Mustafa, ${ }^{6}$ Aye Aye Aung, ${ }^{7}$ Jeremyjones Robles, ${ }^{8}$ Melvin Khee Shing Leow, ${ }^{9}$ \\ Chaicharn Deerochanawong, ${ }^{10}$ Nguyen Thy Khue, ${ }^{11}$ Tran Huu Dang ${ }^{11}$ \\ ${ }^{1}$ Division of Endocrinology, Diabetes and Metabolism, University of the Philippines College of Medicine (UPCM)-Philippine General Hospital \\ ${ }^{2}$ Diabetes, Thyroid and Endocrine Center, St. Luke's Medical Center, Quezon City, Philippines \\ ${ }^{3}$ The Medical City, Pasig City, Philippines \\ ${ }^{4}$ UPCM Department of Pharmacology and Toxicology, Manila, Philippines \\ ${ }^{5}$ Indonesian Society of Endocrinology (ISE) \\ ${ }^{6}$ Malaysian Endocrine and Metabolic Society (MEMS) \\ ${ }^{7}$ Myanmar Society of Endocrinology and Metabolism (MSEM) \\ ${ }^{8}$ Philippine Society of Endocrinology, Diabetes and Metabolism (PSEDM) \\ ${ }^{9}$ Endocrine and Metabolic Society of Singapore (EMSS) \\ ${ }^{10}$ Endocrine Society of Thailand (EST) \\ ${ }^{11}$ Vietnam Association of Diabetes and Endocrinology (VADE)
}

\begin{abstract}
Objectives. The COVID-19 pandemic has made a major impact on hospital services globally, including the care of persons with diabetes and endocrine disorders. The aim of this study is to describe the epidemiology of COVID-19 in the ASEAN Federation of Endocrine Societies (AFES) member countries; to describe challenges, changes and opportunities in caring for patients with endocrine diseases, as well as in fellowship training programs, and endocrinerelated research in the AFES countries.
\end{abstract}

Methodology. The AFES ASEAN Survey Of Needs in Endocrinology (AFES A.S.-O.N.E.) was an open-ended questionnaire that was sent to the presidents and representatives of the AFES member countries by email. Responses from Societies were collated and synthesized to obtain perspectives on the emergent issues in endocrinology in the Southeast Asian region during this pandemic.

Results. The burden of COVID-19 cases varied widely across the AFES member countries, with the least number of cases in Vietnam and Myanmar, and the greatest number of cases in either the most populous countries (Indonesia and the Philippines), or a country with the highest capability for testing (Singapore). The case fatality rate was also the highest for Indonesia and the Philippines at around 6\%, and lowest for Vietnam at no fatalities. The percentage with diabetes among patients with COVID-19 ranged from $5 \%$ in Indonesia to $20 \%$ in Singapore, approximating the reported percentages in China and the United States. The major challenges in managing patients with endocrine diseases involved inaccessibility of health care providers, clinics and hospitals due to the implementation of lockdowns, community quarantines or movement control among the member countries. This led to disruptions in the continuity of care, testing and monitoring, and for some, provision of both preventive care and active management including surgery for thyroid cancer or pituitary and adrenal tumors, and radioactive iodine therapy. Major disruptions in the endocrine fellowship training programs were also noted across the region, so that some countries have had to freeze hiring of new trainees or to revise both program requirements and approaches to training due to the closure of outpatient endocrine clinics. The same observations are seen for endocrine-related researches, as most research papers have focused on the pandemic. Finally, the report ends by describing innovative approaches to fill in the gap in training and in improving patient access to endocrine services by Telemedicine.

Conclusion. The burden of COVID-19 cases and its case fatality rate varies across the AFES member countries but its impact is almost uniform: it has disrupted the provision of care for patients with endocrine diseases, and has also disrupted endocrine fellowship training and endocrine-related research across the region. Telemedicine and innovations in training have been operationalized across the AFES countries in an attempt to cope with the disruptions from COVID-19, but its over-all impact on the practice of endocrinology across the region will only become apparent once we conquer this pandemic.

Key words: survey, Southeast Asia, COVID-19, endocrine care, SARS-CoV-2

ISSN 0857-1074 (Print) | eISSN 2308-118x (Online)

Printed in the Philippines

Copyright $(02020$ by Jasul et al.

Received: May 23, 2020. Accepted: May 23, 2020.

Published online first: May 29, 2020.

https://doi.org/10.15605/jafes.035.01.10
Corresponding author: Assoc. Prof. Gabriel V. Jasul Jr., MD, FPCP, FPSEDM Past President, Philippine Society of Endocrinology, Diabetes and Metabolism Division of Endocrinology, Diabetes and Metabolism, University of the Philippines College of Medicine (UPCM)-Philippine General Hospital

Taft Avenue, Ermita, Manila, Philippines 1000

Tel. No.: +632 5548400 local 2230

E-mail: gjasul@gmail.com

ORCiD: https://orcid.org/0000-0002-9131-1108 


\section{BACKGROUND}

The COVID -19 pandemic literally sent shock waves throughout the world. With an extraordinary speed, SARS-CoV-2 virus spread worldwide with reported total number of confirmed cases exceeding 5 million, claiming a total number of more than 330,000 deaths as of May 22, $2020 .{ }^{1}$ The huge burden on health care systems globally is unprecedented and varies across regions, countries and economies. Well-recognized fields in medicine, namely, infectious diseases, pulmonary and critical care, and emergency medicine, took the lead in the fight against this pandemic. However, as the pandemic has extended over six months now and appears to continue indefinitely, other specialties have become more involved as important risk factors, like hypertension, diabetes and heart disease, and associated conditions, like stroke, hypercoagulability, cytokine storm and multi-organ failure, were identified in COVID-19.

Endocrinologists took an important role in hospital COVID-19 teams as diabetes mellitus has been noted to be present in a significant number of confirmed cases, ranging from 6 to $21 \%$, and even higher rates of up to 36 to $46 \%$ in fatal cases..$^{2-4}$ An international panel of experts in the field of diabetes and endocrinology was recently formed to provide guidance and practical recommendations for the management of diabetes during the pandemic. This panel cited that depending on the global region, 20 to $50 \%$ of COVID-19 patients had diabetes..$^{5}$

The increased worldwide prevalence of diabetes mellitus, the observed greater risk of COVID-19 severity among people with diabetes and the purported mechanisms underlying the association between diabetes and COVID-19 puts endocrinologists at the center of the critical management of these cases. ${ }^{6,7}$ Endocrinologists also have to continue taking care of patients with thyroid diseases, adrenal insufficiency, pituitary disorders, obesity and osteoporosis, among others, as these patients can be similarly infected with the SARS-CoV-2 virus as the general population.

Interestingly, emerging data showed that SARS-CoV-2 cell receptor angiotensin-converting enzyme 2 (ACE2) is expressed in a wide variety of human tissues. ${ }^{8}$ It has been reported that ACE2 is expressed in a number of endocrine organs, namely, the pancreas, thyroid, testis, ovary, adrenals, pituitary and adipose tissue, suggesting the possible involvement of the endocrine system in the multi-organ manifestations of COVID-19.2,9,10 While the evidences on the ACE2 expression in endocrine organs are rather conjectural and derived from early, small studies, especially from other SARS strains, this information can further stimulate the engagement of endocrinologists in COVID-19 management.

Given this background, leading endocrine and diabetes professional organizations have published general recommendations and guidance on the care of patients with diabetes and endocrine diseases during this pandemic. Among these societies were the European Society of Endocrinology, ${ }^{11}$ and the Korean Endocrine Society. ${ }^{2}$ The applicability of these recommendations in the ASEAN region is questionable, as differences in prevalence and clinical presentation of diabetes and endocrine diseases and disparities in health care exist between the
ASEAN countries and the other regions and countries of the world. Generating ASEAN-based recommendations and guidance will thus be a useful undertaking during this pandemic.

As a collaborative project among the member countries of the ASEAN Federation of Endocrine Societies (AFES), we initiated the AFES ASEAN Survey Of Needs in Endocrinology (AFES A.S.-O.N.E.) during the COVID-19 pandemic. The project entailed a brief survey on the emergent issues in endocrinology in the Southeast Asian region during this pandemic (Appendix 1, Survey Form). The objectives of this survey were: first, to obtain basic information on the burden of COVID-19, the burden of diabetes and other endocrine diseases and the challenges in managing them; secondly, to gather data on problems encountered in endocrine fellowship training programs and in endocrine-related research, and thirdly, to determine the utilization of telemedicine and similar initiatives in endocrine care in the AFES member countries during this pandemic.

\section{METHODOLOGY}

The AFES A.S.-O.N.E. is a 7-item open ended questionnaire that solicited information on the following topics from the AFES member countries: country-specific burden of COVID-19 (population estimates and mortality rates); prevalence of diabetes mellitus (DM) and percentage of cases of COVID-19 cases with DM; challenges in diabetes management and in the care of persons with other endocrine diseases; problems and challenges in implementing endocrine fellowship training programs and in pursuing endocrine-related researches; and initiatives to mitigate the problem of physician access such as telemedicine.

Survey forms were sent through electronic mail to the current leaders of the 7 AFES member societies, namely, the Indonesian Society of Endocrinology (ISE), the Malaysian Endocrine and Metabolic Society (MEMS), the Myanmar Society of Endocrinology and Metabolism (MSEM), the Philippine Society of Endocrinology, Diabetes and Metabolism (PSEDM), the Endocrine and Metabolic Society of Singapore (EMSS), the Endocrine Society of Thailand (EST) and the Vietnam Association of Diabetes and Endocrinology (VADE).

Responses from the leaders of these societies were then collated, tabulated and synthesized to put into perspective the current situation of endocrine care in the region during this pandemic.

\section{RESULTS}

\section{Burden of the COVID-19 Pandemic in the AFES Countries}

The burden of COVID-19 pandemic in the AFES countries would be best appreciated by looking at the total number of confirmed cases, the number of recovered cases and the number of deaths vis-à-vis the total population estimate in each country. Likewise, case fatality rate (CFR), also called case fatality risk or case fatality ratio, the proportion of people who die from a specified disease among all individuals diagnosed with the disease over a certain period of time, can be used as a measure of disease severity and is used for prognostication predicting disease 
course or outcome. Tables 1 and 2 summarized the data on COVID-19 in the AFES countries.

\begin{tabular}{|c|c|}
\hline Country & Population Estimate \\
\hline Indonesia (IN) & $273,217,306$ \\
\hline Malaysia (MN) & $32,321,966$ \\
\hline Myanmar (MY) & $54,371,358$ \\
\hline Philippines (PH) & $109,426,100$ \\
\hline Singapore (SG) & $5,845,122$ \\
\hline Thailand (TH) & $69,781,614$ \\
\hline Vietnam (VN) & $97,241,403$ \\
\hline
\end{tabular}

Table 2. COVID-19 statistics in each AFES member country

\begin{tabular}{crrrc}
\hline Country & $\begin{array}{c}\text { Confirmed } \\
\text { Cases }\end{array}$ & $\begin{array}{c}\text { Recovered } \\
\text { Cases }\end{array}$ & Deaths & $\begin{array}{c}\text { Case Fatality } \\
\text { Rate (CFR) }\end{array}$ \\
\hline Indonesia & 20,796 & 5,057 & 1,326 & $6.37 \%$ \\
Malaysia & 7,137 & 5,859 & 115 & $1.61 \%$ \\
Myanmar & 199 & 108 & 6 & $3.02 \%$ \\
Philippines & 13,597 & 3,092 & 857 & $6.30 \%$ \\
Singapore & 30,426 & 12,995 & 23 & $0.08 \%$ \\
Thailand & 3,037 & 2,910 & 56 & $1.84 \%$ \\
Vietnam & 324 & 266 & 0 & $0 \%$ \\
\hline Adapted (as of May 19, 2020) & & & &
\end{tabular}

COVID-19 data from Tables 1 and 2 reflect not only the burden of the pandemic but also the disparities in health care systems, economic structures and political leadership and responsiveness among the AFES countries. The most populous nations, Indonesia and the Philippines, with significant number of confirmed cases (although not the highest), had the most number of fatalities with CFR above $6 \%$. In startling contrast, Singapore, the least populous and with the strongest economy, had the highest number of confirmed cases but one of the lowest CFRs. In between, population-wise, Malaysia and Thailand had positive cases in the thousands but relatively low CFRs under $2 \%$. Myanmar had a very small number of affected cases with a case fatality rate of $3.02 \%$. Vietnam, with a large population size of over 97 million, is definitely the outlier with a low number of affected cases, high recovery rate and zero death despite its proximity to China where SARS-CoV-2 originated. It is widely known that Vietnam declared a travel ban early in January 2020.

Clearly, many factors influenced how the pandemic panned out in each of these countries and in the region in general. Geography, travel patterns, economic systems and political stability will all contribute to the final tally. Factors related to each country's response to the COVID-19 pandemic including public health measures, mass testing and case contact tracing are dependent on the strength of health care systems which in turn are dependent on the economic and political stability in each country. The current status of this pandemic in the region points to much-needed reforms in areas affecting public health and to enhanced regional collaboration.

\section{Burden of Diabetes Mellitus in the AFES Countries}

Diabetes mellitus, the most common endocrine disorder and now an identified risk factor for increased severity and complications in COVID-19, naturally deserves attention in assessing the impact of the pandemic on endocrine care in the region. Diabetes prevalence has been considerably high in the region for several decades now. The reported rates summarized in Table 3 are the most current, as reported by the AFES member societies. Asians have a strong ethnic and genetic predisposition for diabetes and have lower thresholds for the environmental risk factors. Compared to their Western counterpart, they develop diabetes at a younger age and at a lower body mass index and waist circumference. ${ }^{15}$ The recent prevalence rates ranged from around 5\% in Singapore and Vietnam, around 6 to $7 \%$ in the Philippines and Thailand, 10 to $11 \%$ in Indonesia and Myanmar, and the highest at $17.5 \%$ in Malaysia. Certainly, the multi-ethnicity and the sociocultural and religious practices contribute to the increased burden of diabetes in the AFES countries.

It is notable as well that as noted in the data from Indonesia, the Philippines and Vietnam, the prevalence of prediabetes, IFG and/or IGT, is also significantly high. Given this diabetogenic environment, the burden of diabetes is high and magnified by the rapid industrialization in these countries. Preventive strategies are imperative at the primary care level if the goal is to decrease the diabetes burden in the region.

A rough estimation of the proportion of COVID-19 patients with diabetes mellitus showed a low of $5 \%$ in Indonesia and a high of $20 \%$ in Singapore, revised to roughly 8 to $12 \%$ from recent data. In Myanmar, among the 151 confirmed cases, 21 patients, or $13.9 \%$, have diabetes as of 1st May 2020. In Thailand, in a single hospital where 65 COVID-19 positive cases were seen, $15 \%$ had diabetes. In Malaysia, out of 106 COVID-19 deaths, 19 cases, or $17.9 \%$, had diabetes. In the Philippines, the ongoing study of the Philippine College of Physicians is expected to generate results in August 2020. A preliminary unpublished report in one

Table 3. Summary of Diabetes Statistics in AFES member countries

\begin{tabular}{|c|c|c|c|c|}
\hline Country & Diabetes prevalence (\%) & $\begin{array}{l}\text { Impaired Fasting Glucose } \\
\text { (IFG) prevalence (\%) }\end{array}$ & $\begin{array}{l}\text { Impaired Glucose Tolerance } \\
\text { (IGT) prevalence (\%) }\end{array}$ & Source or Reference \\
\hline Indonesia & $\begin{array}{l}10.9 \% \text { (diagnosed } 13.8 \% \\
\text { undiagnosed } 86.2 \% \text { ) }\end{array}$ & $26.3 \%$ & $30.3 \%$ & Basic Health Research 2018, Ministry of Health ${ }^{16}$ \\
\hline Malaysia & $\begin{array}{l}17.5 \% \\
16.8 \%\end{array}$ & & & $\begin{array}{l}\text { NHMS } 2015^{17} \\
\text { IDF Atlas } 2019^{18}\end{array}$ \\
\hline Myanmar & $10.8 \%$ & & & Diabetes, Metabolic Syndrome and Obesity ${ }^{19}$ \\
\hline Philippines & $\begin{array}{c}6.3 \% \\
7.1 \% \\
7.9 \% \text { (based on FBS) }\end{array}$ & $8.2 \%$ & & $\begin{array}{l}\text { IDF Atlas } 2019^{18} \\
\text { Age-adjusted } \% \text { IDF } \\
8^{\text {th }} \text { National Nutrition Survey, FNRI } 2018^{20}\end{array}$ \\
\hline Singapore & $5.5 \%$ & & & 2019 National Data ${ }^{21}$ \\
\hline Thailand & $7.9 \%$ & & & NHES $2018^{22}$ \\
\hline Vietnam & $5.4 \%$ & & $13.7 \%$ & $\begin{array}{l}\text { National Survey } 2012 \\
\text { National Hospital of Endocrinology - Hanoi }{ }^{23}\end{array}$ \\
\hline
\end{tabular}


Philippine government hospital designated as a COVID-19 center noted that $19 \%$ of COVID-19 cases have diabetes. These numbers, while needing validation, approximate the previously reported percentages (6 to $21 \%$ that can reach up to 36 to $46 \%$ ) in China, United States and other countries. ${ }^{2}$ An international panel of experts in the field of diabetes and endocrinology cited that depending on the global region, 20 to $50 \%$ of COVID-19 patients had diabetes. ${ }^{5}$

\section{Challenges in Diabetes Management in the AFES Countries in the Time of COVID-19 Pandemic}

Several areas in diabetes management can be adversely affected during this pandemic depending on the extent of quarantine and other measures imposed to contain the spread of SARS-CoV-2 virus. The availability of medications for the treatment of diabetes, particularly insulins, was not affected in most of the AFES countries. In both Indonesia and the Philippines, the supply of medications did not change in major cities but this may change if the imposed community quarantine will continue and may affect the transport of goods from major cities, especially to far-flung smaller cities. In general, however, there were no reports of shortages in medications so far in the AFES countries.

Access to health care providers, clinics and hospitals can be problematic especially with the imposition of enhanced community quarantine (ECQ) measures, sometimes called "lockdown" or movement control order (MCO), which restricts citizens' movement and travel.

National health coverage in Indonesia allowed routine primary care visits and if necessary, referral for specialty/ tertiary care consults. The imposition of "semi-lockdown" however restricted access to these clinics but two-month worth of maintenance medications were prescribed and supplied to patients to prevent interruption of treatment.

In Malaysia, the MCO resulted in reduction of clinic visits and limited access to the clinics. In major hospitals, Malaysian endocrinologists attend to both COVID and non-COVID admitted cases hence, access to diabetes clinics is temporarily affected. A similar situation was reported in Myanmar.

In the Philippines, with the declaration of ECQ in major cities, many endocrinologists have temporarily closed their outpatient clinics. In major hospitals especially those designated as COVID-19 centers, endocrinologists take part in COVID-19 response teams and direct diabetes management in the critical care setting.

In Malaysia and the Philippines, the use of telemedicine and related virtual modes of patient care and contact was noted to be on the upswing. Notably, during the 2-month long "circuit-breaker (CB)" semi-lockdown in Singapore, only essential services/procedures (defined as those which if not provided would result in significant or rapid deterioration of the patient's medical condition and potentially threaten their health and wellbeing) were allowed. Those deemed as non-essential, such as aesthetic medicine, sports medicine services and joint replacement surgery were prohibited. In Vietnam, even during the 15-day lockdown, hospitals and clinics remained open. Because a significant number of endocrinologists are deployed in COVID-19 units in most, if not all, of the 7 countries, quality diabetes care can be delivered to the hospitalized high-risk patients by early detection and management of diabetic emergencies.

Access to adequate and proper dietary sources is affected by the quarantine measures that prevent patients from going to the markets and groceries and from eating out at restaurants. The food choices may have been reduced in the countries where ECQ. MCO or lockdown were imposed. The upside noted in Malaysia was that consumption of healthier foods prepared at home was higher especially with the observation of Ramadan, the holy month of Muslims during which strict fasting from dawn to sunset is practiced.

In the Philippines, the reliance on take-out and delivery service of restaurants and other food outlets has been on the uptrend in the major cities. Mobile applications, like Food Panda and Grab Food, are now widely used for food deliveries since most people opt to follow stay-at-home instructions. Food access is not a major issue in Singapore, Thailand and Vietnam.

Limitations in physical activity were reported in all countries because of the recommended social distancing and home confinement. Patients and physicians have to rely on home-based exercise activities. The impact of this restriction on exercise and other activities is not huge and as noted, patients were advised alternative exercise programs to do at home.

Financial limitations related to the economic lockdown affects the patients' ability to purchase their maintenance medications. In countries with national health coverage and good health insurance plans, i.e., Indonesia, Malaysia, Singapore, Thailand and Vietnam, access to medications is not a problem. In the Philippines where medications are purchased out-of-pocket by the greater majority of the population, reduced income during the ECQ means reduced allocation for purchasing medications. Prioritizing the medical needs then becomes a challenge. In the minority of private, self-paying patients in the other countries, the economic downturn may have similar effects. In Malaysia, it has been noted that because of the expected economic difficulties, the so-called "private" patients may later opt to transfer and seek health care in government hospitals and clinics.

\section{Challenges in the Management of other Endocrine Disorders in the AFES Countries in the Time of COVID-19 Pandemic}

Treatment of patients with other endocrine disorders has to continue even if these disorders are often stable and do not appear to be adversely affected by COVID-19. Continuity of care for patients with common thyroid diseases, namely, hypothyroidism, hyperthyroidism and thyroid nodules, was not a problem in Malaysia, Thailand, Singapore and Vietnam. In Indonesia, Myanmar, and the Philippines, close follow-up and monitoring of patients, particularly those with hyperthyroidism, became difficult with the limited access to clinics and laboratories. Thyroid function tests and diagnostic imaging procedures cannot be routinely and regularly performed. Patients controlled on stable doses of thyroid medications, whether antithyroid drugs or levothyroxine, are advised to maintain their medications. Virtual consultations were done as 
often as necessary, as reported both in Malaysia and the Philippines. In Singapore, it was noted that a few sporadic cases of hypothyroidism and at least one case of thyroid crisis were seen among COVID-19 patients. Incidental findings of thyroid nodules were discovered during CT scan imaging of the thorax in a few COVID-19 patients. Further work-up, including imaging, fine needle aspirations, and elective surgical procedures are temporarily deferred in all 7 countries.

Thyroid cancer management is not a problem in Malaysia, Myanmar, and Singapore amidst the pandemic. In Indonesia and Vietnam, thyroid cancer patients are managed by surgical oncologists. In the Philippines and Thailand, delay in surgical treatment of thyroid cancer patients is expected and dependent on new surgical and anesthesia policies being enforced because of COVID-19.

Adrenal diseases did not present any major challenge in all of the seven countries during this pandemic. The need for stress dosing of steroids in adrenal insufficiency (AI) is well-established and patients with chronic AI have received specific instructions and sufficient supply of steroids. Since regular follow-up is not possible, as noted in Myanmar and the Philippines, patients are advised to continue their current prescribed doses and to seek consultation at the emergency room if emergency arises. In Singapore, AI was suspected in possibly 5 to $10 \%$ of hospitalized COVID-19 cases who were evaluated with the short Synacthen test (ACTH stimulation test). These cases had no obvious etiologies of AI and had no previous intake of corticosteroids. The possibility of COVID-19 effects on the hypothalamus-pituitary-adrenal (HPA) axis, through direct viral damage or indirect injury from hyper-immune response, was raised and should thus be considered. This is a reasonable assumption based on the findings of hypocortisolism among SARS survivors ${ }^{24}$ and the positive expression of ACE2 in the adrenal glands. ${ }^{8}$ A study on AI and HPA axis in COVID-19 patients is planned at the Philippine General Hospital, a designated COVID center in the Philippines.

Management of pituitary disorders was not a problem in Indonesia, Malaysia, Singapore and Vietnam. Myanmar, Thailand and the Philippines raised concerns regarding lack of follow-up and delay in surgical procedures, similarly an issue also seen in diabetes and the other endocrinopathies. Patients were advised to continue currently prescribed doses and to follow-up after the quarantine period. The possible effects of COVID-19 on the pituitary and the other organs, particularly the gonads, were raised by our Singaporean colleague.

Obesity management was not a major concern in the majority of these countries (Indonesia, Myanmar, the Philippines, Singapore and Vietnam). In Malaysia, the lockdown caused disruption in the prescribed diet, exercise and lifestyle modification among obese patients who already attend weight management programs. In Thailand, patients with obesity experience delay in their followup appointments. In Singapore, obesity rate is roughly estimated at $15 \%$ but it is not a major concern since morbid obesity, particularly body mass index (BMI) in excess of 35 to 40, was not encountered among those stricken with COVID-19. Notably, morbidly obese patients routinely followed up at obesity and bariatric surgery clinics tended to have their regular appointments deferred during the circuit breaker period. In Vietnam, bariatric surgery is not commonly done.

Osteoporosis treatment is not challenging in all the countries during this pandemic. In Myanmar and the Philippines, patients were instructed to continue current prescribed doses and to schedule follow-up after the quarantine period. In Singapore, it was noted that a significant number of the hospitalized COVID-19 patients were over 60 years of age and therefore likely to have osteoporosis. A few cases of hypercalcemia with hypophosphatemia and high intact PTH levels were seen among COVID-19 patients, most likely due to pre-existing parathyroid adenomas. Vitamin D deficiency and secondary hyperparathyroidism were seen in some of the COVID-19 patients as well.

Malnutrition in critical illness was not a commonly seen problem in all the countries. This can be possibly explained by the fact that the critically ill COVID-19 cases were managed in major hospitals which are better equipped. The nutritional management of patients admitted in the smaller hospitals outside the major cities may differ dependent on availability of resources and expertise.

\section{Endocrinology Training Programs in the AFES Countries in the Time of COVID-19 Pandemic}

Clinical training in the COVID-19 era presents many unique challenges particularly in areas of clinical skills enhancement when bedside and face-to-face encounters and hands-on experience are limited both in quantity and in quality. The reality of the "new normal" becomes readily apparent when actual patient encounters are minimized particularly in the ambulatory setting. Many outpatient clinics are temporarily closed until measures to ensure safety of patients and physicians alike are in place. Much of endocrine practice is outpatient-based and the resumption of the usually active diabetes, thyroid and endocrine clinics may not happen anytime soon. The inpatient endocrine service can continue as usual, albeit in a setting restricted by delineation of cases into COVID and non-COVID categories and by the fastidious use of full personal protection equipment (PPEs). The imposeds limitations on patient contact and the drop in hospitalized elective/non-urgent cases will affect the number and the variety of cases encountered by clinicians, consultants and trainees alike. With the onset of the pandemic, these conditions had to be adopted almost overnight in nearly all medical centers, many of which are academic/training institutions.

Given such a dramatic change in the learning environment, the status of the endocrinology training programs in the AFES countries needs to be examined in relation to the important responsibility of the AFES and the AFES member societies of training future endocrinologists. The survey results concerning fellowship training are generally consistent among the AFES countries pointing to new and huge challenges in the training programs except for Thailand and Vietnam. Thailand reported that their training program is still on track but through virtual modes of learning. Vietnam noted that during the lockdown period of 2.5 months, teaching was online using Skype and Zoom, without practical bedside learning and without 
active case discussion. However, after the lockdown was lifted in Vietnam, the training program has resumed as usual in the pre-COVID mode.

Unfortunately, the 5 other AFES countries have to adapt to the new realities of clinical training. Indonesia did not accept new trainees temporarily and their current trainees have problems with doing research and pursuing exchange studies in other countries. Scientific education will continue to be online/web-based. The ISE now conducts webinars for physicians and distributes lay educational materials on diabetes management during the pandemic.

In Malaysia, the Ministry of Health has put a hold on fellowship training programs where no new fellowstrainees will be hired this year. The current fellows will be put on hold for 6 months, will not rotate to other hospitals and will be part of the general medicine and COVID teams in their current hospital. The duration of training of current fellows is thus extended by 6 months, and completion and assessment will be put on hold from April to October this year. Myanmar, on the other hand, is using Zoom and other web-based applications for teaching seminars and case discussions to address the lack of handson training and interactive sessions while practicing social distancing and home stay.

In the Philippines, the PSEDM anticipated a significant drop in the caseload of the current fellows, difficulties in completing research requirements and limitations in teaching conferences and patient advocacy activities. Contingency plans were crafted and these include reduction of fellows' caseload requirement by $50 \%$, modification of nature of research requirement to retrospective, registrybased or meta-analysis, use of online technology for conferences and examinations, the use of social media for patient advocacy and patient education and web-based society conferences.

In Singapore, endocrine fellowship programs will continue in the restructured hospitals but inter-hospital crossover of trainees is not allowed temporarily to reduce the risk of SARS-CoV-2 transmission among trainees and staff and between hospitals. Inter-institutional training through virtual platforms has been put in place to facilitate productive intellectual exchanges. Overseas endocrine fellowship training have been temporarily put on hold due to travel restrictions in place.

\section{Endocrine Research in the AFES Countries in the Time of COVID-19 Pandemic}

Pursuing endocrine-related research can be difficult during this pandemic. All 7 respondents reported the challenges in implementing research activities at this time. Indonesia commented that the present circumstances make it impossible to collect sample, do monitoring and even bring in supplies like reagents for basic research. Malaysia identified several problems related to the safety of research patients from risk of exposure to COVID-19 patients in the hospital and to the COVID-19 status of the research patients since they recruited from the community. For industry-sponsored clinical trials, recruitment of new patients is compromised and patient visits are converted to telephone visits during the MCO period. Investigatorinitiated research has been put on hold and unfortunately, this includes the fellows' research projects which are a mandatory part of their training.

Myanmar noted that due to the lockdown, study patients are not able to come for scheduled visits and since only few outpatient clinics are open, new case finding and recruitment of study patients is very minimal. Study patients may have difficulty in getting their supply of study drugs and treatment interruption or incomplete treatment can happen affecting the study results. Contacting the investigator and/or research staff may be difficult during this time in case of adverse drug events or complications.

The Philippines expects that data collection for prospective studies may be difficult because of limited interaction between patients and doctors. Complete evaluation of study patients may also be limited because of abbreviated study visit to limit potential exposure to COVID-19 cases. Alternatively, different study designs, e.g., online surveys, can be considered as research projects especially for the fellows. Thailand also reported that some study patients cannot come for study visits because of travel ban across provinces. A similar situation is noted in Vietnam where enrolling and following up study patients can be difficult because people prefer to stay at home and transportation is also limited.

In Singapore, all non-COVID-19 research have been put on hold during the circuit breaker/partial lockdown period, severely affecting both basic and clinical research projects. The research funding agencies have allowed deferment of progress reports by 6 months. Research key performance indicators (KPIs) and deliverables are affected by this pandemic. Moreover, the government regulates the shipment of laboratory biological samples to overseas laboratories and the delivery of laboratory consumables such as ELISA assay or antibody test kits, thus, affecting the conduct of research until the government gives permission for resumption of these activities (shipments and deliveries).

\section{Telemedicine and Similar Initiatives in Endocrine Care in the Time of COVID-19 Pandemic}

One of the most interesting developments in health care during this pandemic is the increased reliance on telemedicine and similar resources to mitigate the limited access to physicians for consultations due to the different lockdown restrictions on people's movement. While the usual telephone-based contact and the more recent telehealth resources have already been available, all the 7 AFES countries have now adjusted to this mode of patient-doctor encounter and are slowly adapting to its use in medical education and clinical training. All 7 countries reported the use of web-based/online resources for telemedicine and other related purposes.

Indonesia appreciated the benefits of implementation of telemedicine with the support from their government but noted that there is currently no regulation on payment of fees for teleconsults. Malaysia reported use of virtual meetings among doctors, Zoom-based discussions for teaching the junior physicians, webinars via Facebook live for the public, and email service for patient consultations. Scheduled virtual consultations by phone or video calls have been initiated and continued with patients to include 
review of laboratory results, discussion and prescription and adjustment of medications. Patients who have urgent problems and need to be seen face-to-face are asked to come for scheduled clinic appointments. In Myanmar, patients can contact their endocrinologists via phone, Messenger or Viber messages.

In the Philippines, the PSEDM initiated a Facebook-based patient assistance program that directs the patients to the endocrinologists in their vicinity who are then informed of the consultations. Many of the PSEDM members have engaged their patients through telemedicine applications allowing virtual consultations. Telemedicine has suddenly gained widespread acceptance due to the pandemic and will most likely be a part and parcel of health care moving forward during and after this pandemic. This form of patient encounters appeal to the tech-savvy younger physicians but the traditional patient-doctor contact will be preferred by the more senior physicians who will have to adapt to technology sooner or later.

In Singapore, several telemedicine initiatives have been started to assist mainly in outpatient care and to some extent, in inpatient care as well. We advise caution, however, because the rules of engagement in telemedicine are still being worked out to limit physician exposure to liabilities and other medico-legal issues. In Thailand, the use of telemedicine is for training and webinars for educational purposes. In Vietnam, telemedicine is described as not "high-tech" since most patients still contact their attending physicians through phone calls or messaging. The rare exception is when severe cases are being co-managed by many specialists in different hospitals who are linked through telemedicine.

\section{DISCUSSION}

COVID-19's impact has truly been staggering in many areas of daily living but the health care systems received the heaviest blow from this pandemic. The standards and practices are now radically changed in many, if not all, of disciplines in medicine. Endocrinology has not been spared and endocrinologists are now actively engaged in many aspects of COVID-19 medicine, but largely in the field of diabetes care. Recent publications and rapid reviews on diabetes management in COVID-19 patients attest to the significant burden of diabetes in this current pandemic. The proposed mechanisms of increased risk of COVID-19 severity and complications among patients with diabetes are examined in completed researches and in ongoing investigations. Epidemiologic data, practice recommendations and basic science researches are all part of the COVID-19 publication boom, the majority of which tackles diabetes. ${ }^{2-6,}$ 8-11, 25-30

The generation of ASEAN-derived data can direct the formulation of practice recommendations relevant to the ASEAN region. The AFES A.S.-O.N.E. project is a step towards that direction and entailed a survey on seven areas of concern in endocrine care in AFES countries during the COVID-19 pandemic. From the responses from the current leaders of the 7 AFES member societies, it can be gleaned that the burden of COVID-19 may be aggravated by significant diabetes burden in the region, mirroring the global picture. However, the political and economic structures in these countries clearly influence the disparities in health care systems and the health outcomes during this pandemic. Singapore, with the most robust economy and political stability and lowest population size, had the most number of confirmed cases and yet one of the lowest death rates not only in the region. Vietnam, despite a large population size, had low number of confirmed cases, high recovery rate and zero death, all helped by a stable economy and early and strategic response to COVID-19. Malaysia, Myanmar and Thailand are coping well with the pandemic with low case fatality rates. Indonesia and the Philippines, the most populous nations in the AFES, have the highest death rates.

The other aspects of endocrine care in the AFES countries during the pandemic are similarly affected not only by COVID-19 itself but by the observed disparities in the existing health care systems. Access to endocrinologists and health care facilities is limited in the region during the imposed lockdown but adaptation by patients and physicians averted major health problems through the increased use of telemedicine. Access to medications, adequate dietary sources and physical activity has not been largely affected by the pandemic but if this situation extends indefinitely, it would likely result in shortage of health services and supplies. Management of the endocrine disorders, other than diabetes, is likewise affected by the lack of face-to-face contact and follow-up but virtual consultations are replacing usual patient-physician encounters for now.

Endocrine fellowship training programs in the AFES countries are universally affected by COVID-19 but virtual technology is helpful in addressing the challenges and limitations at this time. Contingency plans are in place to temporarily mitigate the gaps in learning activities and to adjust the minimum requirements in research requirements of the trainees. Endocrine research is adversely affected and non-COVID research is currently limited at this time.

Interest in the involvement of the endocrine organs in COVID-19 pathophysiology is heightened ${ }^{32-34}$ and several observations even in the AFES region support this hypothetically. Aggressive calls for rapid communications and publications on diabetes and endocrine disorders in relation to COVID-19 are being made by both international and regional journals. ${ }^{7,31-34}$

The Journal of the AFES (JAFES) has been promoting endocrine research in the region and its current issue features COVID-19 position statements from Indonesia and the Philippines, ${ }^{27,28}$ perspectives ${ }^{28}$ and inpatient diabetes management guidelines ${ }^{29}$ from the Philippines. Ethical considerations in the conduct of research during the pandemic should also be addressed accordingly. ${ }^{35}$

One of the important findings in this survey was the widespread application of telemedicine and other virtual initiatives in the different areas of endocrinology during this pandemic in the different AFES countries. Patient care, education and research are now arenas of webbased technology circumventing the limitations on actual face-to-face encounters from imposed lockdowns. This adaptation to technology heralds a major reform in health care that happened in response to COVID-19. While virtual technology has been available for quite some 
time now, its use was heightened during this pandemic. Caution must be exercised in applying virtual technology to limit the potential risk of exposing clinicians to liabilities and other medico-legal issues.

\section{Implications of the Survey Results}

Endocrine practice in the AFES countries even during this pandemic actually share more commonalities despite the disparities in health care systems and the differences in economic and political structures among these countries. Our shared commitment to excellence in patient care, training and education and research is strong among the member societies and should be tapped to decrease the differences between these countries. Collaboration between the AFES member societies can be further enhanced by application of virtual technology. Telemedicine will continue to be an important tool in sharing resources among these AFES societies to improve patient care, to promote scientific exchange between institutions and trainees and to encourage endocrine research during and even after the COVID-19 pandemic.

\section{Limitations of the Survey}

This informal survey is limited by the lack of specific outcome measures in the areas of concern, e.g., percentage drop in patient encounters in the endocrine clinics, worsening of laboratory parameters or quality of life measures among patients with diabetes and endocrine disorders, reduction in knowledge base of trainees through formal standardized evaluations or decrease in the number of ongoing researches. Time allowance in completing this survey and inability to validate the responses from the AFES leaders are additional limitations. However, despite these challenges, the survey showed that the AFES countries can come together to complete an important undertaking during this pandemic.

\section{CONCLUSIONS}

AFES A.S.-O.N.E. put in perspective the current situation of endocrine care in the AFES member countries in the time of COVID-19 pandemic. The burden of COVID-19 in these countries reflects the disparities in health care, economic and political stability. The huge burden of diabetes in the region is affected by COVID-19 but adaptability and available expertise averted gaps in the care of patients with diabetes. Management of the other endocrine disorders during this pandemic continued despite limited access to endocrine specialists and facilities. Endocrine fellowship training and endocrine research were affected by lockdown-related limitations on physical encounters and interaction. A welcome development during this pandemic is the widespread and wise application of telemedicine and related virtual technology platforms in the different areas of endocrinology during the pandemic. This survey also highlighted the remarkable opportunity for collaboration among the AFES countries during a most challenging time.

\section{Statement of Authorship}

The authors certified fulfillment of ICMJE authorship criteria.

\section{Author Disclosure}

The authors declared no conflicts of interest.

Funding Source

None.

\section{References}

1. WHO Coronavirus Disease (COVID-19) Dashboard, Johns Hopkins University. Available at https://coronavirus.jhu.edu/map.html.

2. Rhee EJ, Kim JH, Moon SJ, Lee WY. Encountering COVID-19 as endocrinologists. Endocrinol Metab. 2020;35:e1.

3. Gupta R, Ghosh A, Singh AK, Misra A. Clinical considerations for patients with diabetes in time of COVID-19 epidemic. Diabetes Metabo Syndr. 2020;14(3):211-2. PMID: 32172175. PMCID: PMC7102582. https://doi.org/10.1016/j.dsx.2020.03.002

4. CDC COVID-19 Response Team. Preliminary estimates of the prevalence of selected underlying health conditions among patients with Coronavirus disease 2019 - United States, February 12-March 28, 2020. Morbidity and Mortality Weekly Report. 2020; 69(13):382-6. Available at https://www.cdc.gov/mmwr/volumes/69/wr/mm6913e2. htm.

5. Bornstein S, Rubino F, Khunti K, et al. Practical recommendations for the management of diabetes in patients with COVID-19. Lancet Diabetes Endocrinol. 2020;8(6):546-50. PMID: 32334646. PMCID: PMC7180013. https://doi.org/10.1016/S2213-8587(20)30152-2.

6. Hussain A, Bishwajit B, Moreira NCdV. COVID-19 and diabetes: knowledge in progress. Diabetes Res Clin Pract. 2020;162:108142. PMID: 32278764. PMCID: PMC7144611. https://doi.org/10.1016/j. diabres.2020.108142.

7. Bloomgarden ZT. Diabetes and COVID-19. J Diabetes. 2020;12(4):3478. PMID: 32162476. https://doi.org/10.1111/1753-0407.13027.

8. Li M-Y, Li L, Zhang Y, Wang XS. Expression of the SARS-CoV-2 cell receptor gene ACE2 in a wide variety of human tissues. Infect Dis Poverty. 2020;9(45). PMID: 32345362. PMCID: PMC7186534. https:// doi.org/10.1186/s40249-020-00662-x.

9. Pal R, Banerjee M. COVID-19 and the endocrine system: Exploring the unexplored. J Endocrinol Invest. 2020;1-5. PMID: 32361826. PMCID: PMC7195612. https://doi.org/10.1007/s40618-020-01276-8.

10. Kaiser UB, Mirmira RG, Stewart PM. Our response to COVID-19 as endocrinologists and diabetologists. J Clin Endocrinol Metab. 2020;105(5):1299-1301. PMID: 32232480. PMCID: PMC7108679. https:// doi.org/10.1210/clinem/dgaa148.

11. Puig-Domingo M, Marazuela M, Giustina A. COVID-19 and endocrine diseases. A statement from the European Society of Endocrinology. Endocrine. 2020;68(1):2-5. PMID: 32279224. PMCID: PMC7150529. https://doi.org/10.1007/s12020-020-02294-5.

12. United Nations Population Division Live Estimates, as of May 22, 2020

13. COVID-19 Worldwide Dashboard - WHO Live World Statistics. Available at https://covid19.who.int/?gclid=CjwKCAjw2a32BRBXEiw AUcugiGlzLlwiCfk0eZ2argIiuSC2UTcX9vvBXgJPj366sBMXiuOeWs8 MyBoCY2UQAvD BwE.

14. Oxford COVID-19 Evidence Service - CEBM. Available at https:// www.cebm.net/covid-19/.

15. Ramachandran A, Snehalatha C, Shetty AS, Nanditha A. Trends in prevalence of diabetes in Asian countries. World J Diabetes. 2012;3(6):110-7. PMID: 22737281. PMCID: PMC3382707. https://doi org/10.4239/wjd.v3.i6.110.

16. Ministry of Health. Indonesia Basic Health Research 2018.

17. National Health and Morbidity Survey (NHMS) 2015. http://iku.moh. gov.my/index.php/research-eng/list-of-research-eng/iku-eng/nhmseng/nhms-2015.

18. IDF Atlas 9th ed, 2019. https://www.diabetesatlas.org/en/.

19. Latt TS, Zaw KK, Ko K, et al. Diabetes Metab Syndr Obes. 2019;12: 291-8. PMID: 30881072. PMCID: PMC6407671. https://doi.org/10.2147/ DMSO.S156270.

20. Food and Nutrition Research Institute. 8th National Nutrition Survey (NNS), 2018.

21. 2019 National Data.

22. Thai National Health Examination Surveys (NHES), 2018.

23. National Survey 2012, National Hospital of Endocrinology- Hanoi, Vietnam.

24. Leow MK, Kwek DS, Ng AW, et al. Hypocortisolism in survivors of severe acute respiratory syndrome (SARS). Clin Endocrinol (Oxf). 2005;6(2):197-202. PMID: 16060914. PMCID: PMC7188349. https://doi.org/10.1111/j.1365-2265.2005.02325.x.

25. Muniyappa R, Gubbi S. COVID-19 pandemic, coronaviruses, and diabetes mellitus. Amer J Physiology Endocrinol Metab. 2020;318(5):E736-41. PMID: 32228322. PMCID: PMC7191633. https:// doi.org/dp10.1152/ajpendo.00124.2020.

26. Philippine Society of Endocrinology, Diabetes and Metabolism. Position statement on COVID-19 infection and diabetes. J ASEAN Fed Endocr Soc. 2020;35(1). https://doi.org/10.15605/jafes.035.01.02.

27. Indonesian Society of Endocrinology. Position statement on how to manage patients with diabetes and COVID-19. J ASEAN Fed Endocr Soc. 2020;35(1):49-51. https://doi.org/10.15605/jafes.035.01.03.

28. Arcellana AE, Jimeno CA. Challenges and opportunities for diabetes care in the Philippines in the time of the COVID-10 pandemic. J ASEAN Fed Endocr Soc. 2020;35(1):55-7. https://doi.org/10.15605/ jafes.035.01.04

29. Jimeno CA, Anonuevo-Cruz MC, Uy AB, et al. UP-Philippine General Hospital Division of Endocrinology, Diabetes and Metabolism 
Consensus Recommendations for In-Patient Management of Diabetes Mellitus among Persons with COVID-19. J ASEAN Fed Endocr Soc. 2020;35(1):14-25. https://doi.org/10.15605/jafes.035.01.05.

30. Hamdy O, Gabbay RA. Early observation and mitigation of challenges in diabetes management of COVID-19 patients in critical care units. Diabetes Care. 2020. https://doi.org/10.2337/dc20-0944.

31. Simoni M, Hofmann MC. The COVID-19 pandemics: Shall we expect andrological consequences? A call for contributions to Andrology. Andrology. PMID: 32302464. https://doi.org/10.1111/andr.12804.

32. Brancatella A, Ricci D, Viola N, Sgro D, Santini F, Latrofa F. Subacute thyroiditis after SARS-CoV-2 infection. J Clin Endocrinol Metab. 2020. https://doi.org/10.1210/clinem/dgaa276.

33. Yang W, Wang C, Shikora S, Kow L. Recommendations for metabolic and bariatric surgery during the COVID-19 pandemic from IFSO. Obe Surg. PMID: 32291701. PMCID: PMC7155392. https://doi.org/10.1007/ s11695-020-04578-1.

34. Filetti, S. The COVID-19 pandemic requires a unified global response. Endocrine. 2020;68(1):1. PMID: 32253680. PMCID: PMC7133773. https://doi.org/10.1007/s12020-020-02293-6.

35. Reyes MVT. Research in the time of COVID-19 pandemic: Challenges to research ethics committees. J ASEAN Fed Endocr Soc. 2020;35(1): 29-32. https://doi.org/10.15605/jafes.035.01.07.

Authors are required to accomplish, sign and submit scanned copies of the JAFES Author Form consisting of: (1) Authorship Certification, that authors contributed substantially to the work, that the manuscript has been read and approved by all authors, and that the requirements for authorship have been met by each author; (2) the Author Declaration, that the article represents original material that is not being considered for publication or has not been published or accepted for publication elsewhere, that the article does not infringe or violate any copyrights or intellectual property rights, and that no references have been made to predatory/ suspected predatory journals; (3) the Author Contribution Disclosure, which lists the specific contributions of authors; and (4) the Author Publishing Agreement which retains author copvright, grants publishing and distribution rights to JAFES, and allows JAFES to apply and enforce an Attribution-Non-Commercial Creative Commons user license. Authors are also required to accomplish, sign, and submit the signed ICMJE form for Disclosure of Potential Conflicts of Interest. For original articles, authors are required to submit a scanned copy of the Ethics Review Approval of their research as well as registration in trial registries as appropriate. For manuscripts reporting data from studies involving animals, authors are required to submit a scanned copy of the Institutional Animal Care and Use Committee approval. For Case Reports or Series, and Images in Endocrinology, consent forms, are required for the publication of information about patients; otherwise, appropriate ethical clearance has been obtained from the institutional review board. Articles and any other material published in the JAFES represent the work of the author(s) and should not be construed to reflect the opinions of the Editors or the Publisher.

\section{Appendix 1. A Brief Survey on the Emergent Endocrine Issues in Southeast Asia in the Midst of COVID-19 Pandemic}

1. What is the latest COVID-19 statistics in your country? (Total number of cases, number of deaths, number of recovered cases). Please include date of latest report. Please note as well as the latest population estimate in your country.

2. Diabetes mellitus is cited as an important co-morbid condition among COVID-19 cases in publications and reports.

A. What is the prevalence of diabetes mellitus in your country?

B. What is the estimated number/percentage of COVID-19 patients who also have diabetes mellitus in your country?

3. What are the identified challenges in diabetes management during this pandemic? Please check all applicable choices and explain, if necessary.

A. Availability of medications, especially insulins

B. Access to endocrinologists and primary care doctors and to treatment centers/hospitals/clinics

C. Access to adequate and proper dietary sources

D. Limitations in physical activity, especially due to social distancing

E. Limitations in finances for medications, due to economic lockdown

F. Others

4. Are there identified challenges in the management of other endocrine diseases because of COVID-19? YES or NO choices. If the answer is yes, please specify. You may adapt the choices for diabetes management above.

A. Thyroid diseases in general (hypothyroidism, hyperthyroidism, benign nodules)

B. Thyroid cancer

C. Adrenal diseases, especially adrenal insufficiency

D. Pituitary diseases

E. Obesity

F. Osteoporosis and other bone and mineral disorders

G. Malnutrition in critical illness

H. Others

5. Are there identified problems now in continuing endocrine fellowship training programs in your country? YES or NO. Please explain and discuss briefly. Please share strategies in place or being planned to address these issues related to training.

6. Are there identified problems in pursuing endocrine-related research during this pandemic? YES or NO. Please explain and discuss briefly.

7. Are there telemedicine and similar initiatives in place in your country to mitigate the limitation in access to physicians, especially endocrinologists during this pandemic. YES or NO. Please discuss briefly and share your experiences.

Please feel free to add any comments that might have not been covered by the 7 questions in this survey. It will also be most appreciated if you can provide resources and/or links to relevant treatment algorithms, guidelines and consensus statements that are being utilized in your country during this pandemic. Again, thank you very much! 